\title{
Reaction Conditions for Maximal Cyclodextrin Production by Cyclodextrin Glucanotransferase from Bacillus megaterium
}

\author{
BORIANA Y. ZHEKOVA ${ }^{1 *}$ and VESELIN S. STANCHEV ${ }^{2}$ \\ ${ }^{1}$ Department of Biochemistry and Molecular Biology, University of Food Technologies, Plovdiv, Bulgaria \\ ${ }^{2}$ Department of Automatics, Information and Control Systems, University of Food Technologies \\ Plovdiv, Bulgaria
}

Received 14 September 2010, revised 7 April 2011, accepted 15 April 2011

Abstract

The effect of the reaction conditions (substrate concentration, enzyme dosage, and $\mathrm{pH}$ ) on cyclodextrin production by cyclodextrin glucanotransferase from Bacillus megaterium was investigated by applying mathematical modeling methods. Adequate models were developed and they were used for determination of the optimal conditions for maximal formation of $\beta$-cyclodextrins at minimal concentrations of $\alpha$ - and $\gamma$-cyclodextrins. The main factor affecting the ratio of the products was $\mathrm{pH}$ of the reaction mixture. At $\mathrm{pH} 9$ the enzyme formed mainly $\beta$ - and $\gamma$-cyclodextrins and the ratio $\alpha: \beta: \gamma$ was 2.6:83.5:13.9; at pH 5 the ratio changed to 8.6:84.6:6.8. Mathematical models were used for determination of the conditions for maximal conversion of the substrate into cyclodextrins. $45.88 \%$ conversion of starch was achieved at $5 \%$ substrate concentration, $3.5 \mathrm{U} / \mathrm{g}$ enzyme dosage, and $\mathrm{pH} 7.4$.

Ke y words: cyclodextrins, cyclodextrin glucanotransferase, mathematical modeling, Bacillus megaterium

\section{Introduction}

Cyclodextrins (CD) are cyclic nonreducing oligosaccharides composed of $\alpha-1,4$-linked glucose units, which are designated $\alpha, \beta$ and $\gamma$, according to the number of glucose units $(6,7$ or 8 , respectively). CD molecules possess a hydrophobic inner cavity, in which hydrophobic compounds can be incapsulated. As a result, the properties of the guest molecules are altered. This ability of $\mathrm{CD}$ determines their broad application in different areas of industry. They are applied in food industry for removal of unwanted flavour and aroma, for protection of guest molecules from degradation under the action of light and heat, for reduction of side effects of drug formulations, for improvement of water solubility of insoluble compounds, for stabilization of volatile substances, etc. (Del Valle, 2004).

$\mathrm{CD}$ are produced by enzyme conversion of starch with cyclodextrin glucanotransferase (CGTase, 2.4.1.19). CGTase is a unique enzyme produced only by microorganisms, usually Bacillus species (Tonkova, 1998). All known CGTases form the three types of CD, but in different ratio (Leemhuis et al., 2010; Qi and Zimmermann, 2005). According to the predominant type of CD formed they are classified as $\alpha-, \beta$ - and
$\gamma$-CD. The product specificity of CGTases determines their application for production of certain type of $\mathrm{CD}$.

The yield and ratio of $\mathrm{CD}$ depend on the properties of CGTase, kind of substrate used (Alves-Prado et al., 2008), its preliminary treatment (Goh et al., 2007; Pishtiyski and Zhekova, 2006; Sakinah et al., 2009) and reaction conditions (Martins and Hatti-Kaul, 2003; Matioli et al., 2001). A great number of reports, describing the effect of the reaction conditions on the production of the predominant type of $\mathrm{CD}$ and determination of the optimal parameters of the process, are available (Charoenlap etal., 2004; Gawande and Patkar, 2001; Rauf et al., 2008; Szerman et al., 2007). However, there is no data for determination of the conditions for maximal production of certain type of $\mathrm{CD}$ at the terms of minimal amounts of concomitant types of CD. This is a subject of a certain interest, as the presence of several types of $\mathrm{CD}$ in the reaction mixture requires separation and purification of the desired product.

On the other hand the enzyme reaction can be directed to formation of a certain type of CD by selection of proper conditions. Additionally this fact allows the enzyme to be used not only for production of the predominant type of $\mathrm{CD}$, but also for production of the concomitant types of $\mathrm{CD}$. The enzyme from Bacillus

\footnotetext{
* Corresponding author: B.Y. Zhekova, 26 Maritza Boulevard, 4002 Plovdiv, Bulgaria; phone: (+359) 32 603 605; fax: (+359) 32 644 102; e-mail: zhekova_b@yahoo.com
} 
megaterium used in this study formed $\beta-\mathrm{CD}$ as the predominant product of the cyclization reaction (Zhekova et al., 2008; Zhekova et al., 2009).

The aim of the current research was establishment of an optimal working point for the process of CD production, which determines maximal amount of $\beta-C D$ at the conditions of minimal presence of $\alpha$ - and $\gamma-C D$, and determination of the conditions for main formation of $\alpha$ - and $\gamma$-CD and maximal conversion of starch into CD.

\section{Experimental}

\section{Material and Methods}

Substrate and enzyme preparation. The substrate for CD production was corn starch obtained from Amilum. The enzyme preparation used was a crude CGTase from B. megaterium (from the collection of the Department of Biochemistry and Molecular Biology, University of Food Technologies, Plovdiv) with activity of $2.54 \mathrm{U} / \mathrm{ml}$. The cultivation of the strain and biosynthesis of the enzyme were performed as described in previous research (Pishtiyski et al., 2008).

Enzyme reaction. Substrate solutions were prepared in citrate-phosphate buffer ( $\mathrm{pH} 5.0-9.0)$, in a manner allowing the desired concentration to be reached after the addition of the enzyme preparation. The substrate was gelatinized in a steam water bath for $10 \mathrm{~min}$, cooled to $30^{\circ} \mathrm{C}$ and the necessary amount of CGTase was added. The enzyme reaction was conducted in 100-ml Erlenmeyer flasks containing $50 \mathrm{ml}$ of reaction medium, at $30^{\circ} \mathrm{C}$ on a reciprocal shaker for $10 \mathrm{~h}$. CGTase was inactivated by boiling for $10 \mathrm{~min}$ in a water bath and the content of $\alpha$-, $\beta$ - and $\gamma$-CD formed was determined.

Experimental design. The effect of starch concentration, CGTase dosage and $\mathrm{pH}$ on cyclodextrin production was studied by using optimal composite design with distance from the centre of the design space to a factorial point \pm 1 (Mason et al., 2003).

The static of the process was described by using nonlinear mathematical models of the type:

$$
Y=\beta_{0}+\sum_{i=1}^{k} \beta_{i} \cdot x_{i}+\sum_{i=1}^{k} \beta_{i i} \cdot x_{i}^{2}+\sum_{i=1}^{k-1} \sum_{j=2}^{k} \beta_{i j} \cdot x_{i} \cdot x_{j}
$$

where the variable $\hat{Y}$ is the predicted response, $x_{i}$ and $x_{i}$ are the independent variables, $\beta_{0}$ is the offset term, $\beta_{i}$ is the linear effect, $\beta_{i j}$ is the interaction effect, $\beta_{i i}$ is the squared term and $k$ is the number of the independent variables.

Real and coded values of the independent variables and their variation intervals are presented in Table I.

The test for statistical significance of the regression coefficients and the models developed was perfor-
Table I

Variation intervals of the independent variables

\begin{tabular}{|l|c|c|c|}
\hline Independent variable & -1 & 0 & +1 \\
\hline$x_{1}-\operatorname{starch}(\%)$ & 1 & 3 & 5 \\
\hline$x_{2}-$ CGTase (U/g) & 0.5 & 2 & 3.5 \\
\hline$x_{3}-\mathrm{pH}$ & 5 & 7 & 9 \\
\hline
\end{tabular}

med using ANOVA. For determination of the function maxima MATLAB 6.0 was used.

Assays. CGTase activity was determined by Kestner's method (Kestner etal., 1989) as described previously (Zhekova et al., 2008).

The concentration of $\alpha-C D$ was determined by the method with methyl orange (Lejeune et al., 1989), of $\beta$-CD - with phenolphthalein (Kestner et al., 1989), of $\gamma$-CD - with bromcresol green (Kato and Horikoshi, 1984).

CD concentrations were confirmed by HPLC system Shimadzu 20 AHT with refractive index detector. For estimation of $\alpha$-, and $\gamma$-CD YMC-Pack ODS-AQ column (YMC Europe) was used. The mobile phase was a mixture of methanol and water in a ratio of 3:97 with a flow rate of $1.3 \mathrm{ml} / \mathrm{min}$, and the column temperature was $30^{\circ} \mathrm{C}$. $\beta$-CD were analyzed on Ultrahydrogel column (Waters), at $30^{\circ} \mathrm{C}$, and bidestiled water as a mobile phase with a flow rate of $0.8 \mathrm{ml} / \mathrm{min}$.

\section{Results and Discussion}

The effect of the investigated factors in the variation intervals, presented in Table I on $\alpha-, \beta$ - and $\gamma$-CD production was analyzed by using nonlinear regression equations (1).

The optimal composite design, the experimental data for $\alpha$-, $\beta$ - and $\gamma$-CD (designated $Y_{\alpha}, Y_{\beta}$ and $Y_{\gamma}$ respectively) and the corresponding predicted values $\left(\hat{Y}_{\alpha}, \hat{Y}_{\beta}, \hat{Y}_{\gamma}\right)$ are presented in Table II.

The following regression equations were obtained after removal of the insignificant terms:

$$
\begin{aligned}
& \hat{Y}_{\alpha}=1.703+0.206 . x_{1}+0.19 . x_{2}-0.376 . x_{3}-0.16 . x_{13}- \\
& -0.13 \cdot x_{23}-0.42 \cdot x_{1}^{2}-0.3 \cdot x_{2}^{2}-0.12 \cdot x_{3}^{2} \\
& \hat{Y}_{\beta}=12.571+5.234 . x_{1}+3.138 \cdot x_{2}+1.669 . x_{12}- \\
& -1.693 . x_{1}^{2}-1.973 . x_{2}^{2} \\
& \hat{Y}_{\gamma}=1.832+0.521 . x_{1}+0.332 . x_{2}+0.716 . x_{3}+ \\
& +0.156 \cdot x_{12}+0.099 \cdot x_{13}-0.249 \cdot x_{2}^{2}-0.249 . x_{3}^{2}
\end{aligned}
$$

The analysis of variance (Table III) showed that the regression equations are statistically significant at 95\% confidence level.

The extremums of equations (2), (3) and (4) are presented in Table IV.

It was noticed that they were achieved at different values of the independent variables. This confirmed the 
Table II

Optimal composite design for three factors and three levels of their variation

\begin{tabular}{|c|c|c|c|c|c|c|c|c|c|}
\hline \multirow{2}{*}{ № } & \multirow{2}{*}{$x_{1}$} & \multirow{2}{*}{$x_{2}$} & \multirow{2}{*}{$x_{3}$} & \multicolumn{2}{|c|}{$\alpha-\mathrm{CD}(\mathrm{mg} / \mathrm{ml})$} & \multicolumn{2}{|c|}{$\beta-\mathrm{CD}(\mathrm{mg} / \mathrm{ml})$} & \multicolumn{2}{|c|}{$\gamma$-CD $(\mathrm{mg} / \mathrm{ml})$} \\
\hline & & & & $Y_{\alpha}$ & $\hat{Y}_{\alpha}$ & $Y_{\beta}$ & $\hat{Y}_{\beta}$ & $Y_{\gamma}$ & $\hat{Y}_{\gamma}$ \\
\hline 1 & -1 & -1 & -1 & 0.38 & 0.55 & 2.98 & 2.20 & 0.15 & 0.02 \\
\hline 2 & -1 & -1 & 1 & 0.32 & 0.38 & 2.46 & 2.20 & 1.20 & 1.25 \\
\hline 3 & -1 & 1 & -1 & 1.24 & 1.19 & 5.30 & 5.14 & 0.32 & 0.37 \\
\hline 4 & -1 & 1 & 1 & 0.40 & 0.50 & 5.52 & 5.14 & 1.61 & 1.61 \\
\hline 5 & 1 & -1 & -1 & 1.48 & 1.28 & 10.48 & 9.33 & 0.66 & 0.55 \\
\hline 6 & 1 & -1 & 1 & 0.52 & 0.47 & 8.86 & 9.33 & 2.07 & 2.18 \\
\hline 7 & 1 & 1 & -1 & 1.83 & 1.92 & 17.29 & 18.95 & 1.42 & 1.53 \\
\hline 8 & 1 & 1 & 1 & 0.61 & 0.59 & 20.78 & 18.95 & 3.14 & 3.16 \\
\hline 9 & -1 & 0 & 0 & 1.36 & 1.08 & 4.07 & 5.64 & 1.27 & 1.31 \\
\hline 10 & 1 & 0 & 0 & 1.32 & 1.49 & 15.26 & 16.11 & 2.47 & 2.38 \\
\hline 11 & 0 & -1 & 0 & 1.20 & 1.21 & 5.75 & 7.46 & 1.18 & 1.25 \\
\hline 12 & 0 & 1 & 0 & 1.72 & 1.59 & 13.02 & 13.74 & 2.09 & 1.92 \\
\hline 13 & 0 & 0 & -1 & 1.98 & 1.96 & 11.56 & 12.57 & 0.79 & 0.87 \\
\hline 14 & 0 & 0 & 1 & 1.30 & 1.21 & 11.25 & 12.57 & 2.48 & 2.33 \\
\hline 15 & 0 & 0 & 0 & 1.70 & 1.70 & 14.88 & 12.57 & 1.61 & 1.83 \\
\hline 16 & 0 & 0 & 0 & 1.78 & 1.70 & 15.38 & 12.57 & 1.51 & 1.83 \\
\hline 17 & 0 & 0 & 0 & 1.52 & 1.70 & 12.81 & 12.57 & 2.06 & 1.83 \\
\hline 18 & 0 & 0 & 0 & 1.58 & 1.70 & 11.97 & 12.57 & 1.97 & 1.83 \\
\hline
\end{tabular}

Table III

Statistical analysis results according to Anova

\begin{tabular}{|l|c|c|c|c|c|c|c|c|c|c|c|c|}
\hline & \multicolumn{4}{|c|}{ Equation (2) } & \multicolumn{4}{c|}{ Equation (3) } & \multicolumn{4}{c|}{ Equation (4) } \\
\hline Parameter & $\mathrm{df}$ & $\mathrm{SS}$ & $\mathrm{MS}$ & $\mathrm{F}_{\text {sign }}$ & $\mathrm{df}$ & $\mathrm{SS}$ & $\mathrm{MS}$ & $\mathrm{F}_{\text {sign }}$ & $\mathrm{df}$ & $\mathrm{SS}$ & $\mathrm{MS}$ & $\mathrm{F}_{\text {sign }}$ \\
\hline Regression & 8 & 4.83 & 0.60 & $8.7 \mathrm{E}-5$ & 5 & 441 & 88.2 & $1.2 \mathrm{E}-6$ & 7 & 10.1 & 1.44 & $1.9 \mathrm{E}-6$ \\
\hline Residual & 9 & 0.28 & 0.03 & & 12 & 31.5 & 2.6 & & 10 & 0.37 & 0.04 & \\
\hline Total & 17 & 5.11 & & & 17 & 473 & & & 17 & 10.4 & & \\
\hline
\end{tabular}

Df - Degree of freedom; SS - Sum square; MS - Mean square; $F_{\text {sign }}-$ F significance

Table IV

Extremum of equations (2), (3) and (4)

\begin{tabular}{|c|c|c|c|c|c|c|}
\hline \multirow{2}{*}{ Extremum } & \multicolumn{2}{|c|}{ Equation (2) } & \multicolumn{2}{c|}{ Equation (3) } & \multicolumn{2}{c|}{ Equation (4) } \\
\cline { 2 - 7 } & $\hat{Y}_{\alpha}^{\text {min }}$ & $\hat{Y}_{\alpha}^{\text {max }}$ & $\hat{Y}_{\beta}^{\text {min }}$ & $\hat{Y}_{\beta}^{\text {max }}$ & $\hat{Y}_{\gamma}^{\text {min }}$ & $\hat{Y}_{\gamma}^{\text {max }}$ \\
\hline Value $(\mathrm{mg} / \mathrm{ml})$ & 0.381 & 2.12 & 2.20 & 18.95 & 0.02 & 3.16 \\
\hline Conditions: $x_{1}$ & -1 & 0.436 & -1 & 1 & -1 & 1 \\
\hline $\mathrm{x}_{2}$ & -1 & 0.533 & -1 & 1 & -1 & 0.98 \\
\hline $\mathrm{x}_{3}$ & 1 & -1 & $-1 \div 1$ & $-1 \div 1$ & -1 & 1 \\
\hline
\end{tabular}

hypothesis that the ratio of $\alpha-, \beta$ - and $\gamma-\mathrm{CD}$ can be controlled by a change in the reaction conditions.

The mathematical models obtained can be interpreted in several aspects. It is of great interest to determine the working conditions at which equations (2), (3) and (4) achieved their maximal value. This allows the models to be used for selection of conditions at which maximal amount of a certain CD type is produced at beforehand known concentration of other types of $\mathrm{CD}$.
The enzyme used in this study formed mainly $\beta$-CD. For these reasons the models developed were interpreted in the respect of production of maximal amount of $\beta-C D$ at minimal concentration of $\alpha-$ and $\gamma$-CD.

Minimal values of $\hat{Y}_{\alpha}$ and $\hat{Y}_{\nu}$ were achieved at equal levels of the first and second independent variable $x_{1}=-1$ and $x_{2}=-1$ (Table IV). However, under these conditions $\hat{Y}_{\beta}$ also reached its minimum. Consequently, these two factors could not be used for control of the 


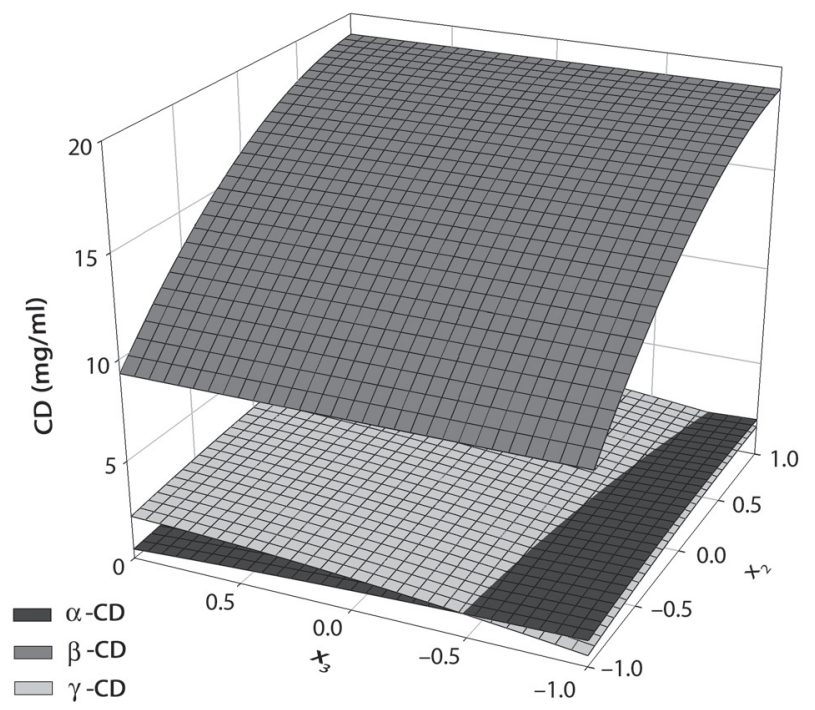

Fig. 1. Effect of CGTase concentration and $\mathrm{pH}$ on $\mathrm{CD}$ production (5.0\% starch).

ratio of $\alpha-, \beta$ - and $\gamma$-CD. This result is normal taking into consideration the fact that increase in substrate and enzyme concentrations lead to enhancement of the product yield in enzyme reactions.

With regard to the third independent variable $(\mathrm{pH}$ of the reaction mixture) there were significant differences at the values at which $\hat{Y}_{\alpha}$ and $\hat{Y}_{\gamma}$ reached their minimums. $\hat{Y}_{\alpha}{ }^{\mathrm{min}}=0.38 \mathrm{mg} / \mathrm{ml}$ was achieved at $x_{3}=1$, and $\hat{Y}_{y}{ }^{\text {min }}=0.02 \mathrm{mg} / \mathrm{cm}^{3}-$ at $x_{3}=-1$ (Table IV). On the other hand formation of $\beta$-CD did not depend on $\mathrm{pH}$ of reaction mixture - the concentration of $\beta-\mathrm{CD}$ was maximal at the whole investigated interval of $\mathrm{pH}$ (5.0-9.0). These results allowed the process for CD production to be performed at reaction conditions which ensured formation of only two types of CD ( $\alpha$ and $\beta)$ or ( $\gamma$ and $\beta)$.

The minimal values of $\alpha$ - and $\gamma$-CD concentrations were formed at the lowest levels of $x_{1}$ and $x_{2}$, which also had a negative effect on $\beta-C D$. For these reasons the values of the functions were calculated at the highest levels of $x_{1}$ and $x_{2}$, and variation of $x_{3}$.

When the process was performed at $x_{1}=1, x_{2}=1$ and $x_{3}=1$, the predicted concentrations of CD according to equations (2), (3) and (4) were as followed: $\hat{Y}_{\alpha}=0.59 \mathrm{mg} / \mathrm{ml}, \hat{Y}_{\beta}=18.95 \mathrm{mg} / \mathrm{ml}$ and $\hat{Y}_{\gamma}=3.16 \mathrm{mg} / \mathrm{ml}$. Since at these conditions the concentration of $\alpha$-CD was only $3.1 \%$ in regard to $\beta$-CD concentration, they were considered as optimal for production of $\beta-C D$ in the absence of $\alpha$. These results were confirmed by performing 4 parallel experiments and the following mean values of $\alpha$-, $\beta$ - and $\gamma$-CD were registered: $Y_{\alpha}^{\exp }=0.56 \mathrm{mg} / \mathrm{ml}$, $Y_{\beta}^{\exp }=18.79 \mathrm{mg} / \mathrm{ml}, Y_{\gamma}^{\exp }=3.13 \mathrm{mg} / \mathrm{ml}$. A test for equality of the mathematical expectation of the experimental results and the predicted data was conducted. As the values of $t_{\text {calc }}\left(t_{\alpha, \text { calc }}=1.058, t_{\beta \text { calc }}=0.392, t_{\gamma, \text { calc }}=0.821\right.$ respectively) were lower than $t_{\text {crit }}=3.182$ at $95 \%$ significant level and degree of freedom 3, it was established that there was no statistically significant difference between the experimental and predicted results.

It can be concluded that at starch concentration of 5.0\%, enzyme dosage $3.5 \mathrm{U} / \mathrm{g}$ and $\mathrm{pH} 9$ CGTase from Bacillus megaterium formed mainly $\beta$ - and $\gamma$-CD and the ratio $\alpha: \beta: \gamma$ was $2.6: 83.5: 13.9$. At these conditions a-CD were only $2.6 \%$ of the total CD amount.

For determination of the conditions at which the enzyme formed maximal amount $\beta-\mathrm{CD}$ at minimal $\gamma$-CD concentration, the predicted values of equations (2), (3) and (4) at $x_{1}=1, x_{2}=1, x_{3}=-1$ were calculated. These were $\hat{Y}_{\alpha}=1.92 \mathrm{mg} / \mathrm{ml}, \hat{Y}_{\beta}=18.95 \mathrm{mg} / \mathrm{ml}$ and $\hat{Y}_{\gamma}=1.53 \mathrm{mg} / \mathrm{ml}$, respectively. The experimental results (mean value of 4 experiments) under these conditions were as follows: $Y_{\alpha}^{\exp }=1.87 \mathrm{mg} / \mathrm{ml}, Y_{\beta}^{\exp }=18.21 \mathrm{mg} / \mathrm{ml}$, $Y_{\gamma}^{\exp }=1.48 \mathrm{mg} / \mathrm{ml}$. No statistical difference was observed between the experimental and predicted data $\left(t_{\alpha, \text { calc }}=1.475, t_{\beta \text { calc }}=2.039\right.$ and $t_{\gamma, \text { calc }}=1.65$ were lower than $\left.t_{\text {crit }}=3.182\right)$. The ratio of the three types of CD was 8.6:84.6:6.8. There was no significant decrease in $\gamma$-CD concentration and its percent ratio was close to the value of $\alpha-C D$. The analysis of (2), (3) and (4) showed that the amount of $\gamma$-CD can be decreased only by a change in $x_{1}$ and $x_{2}$. However, these two factors influenced the concentration of $\beta-C D$ in a similar way. For example at the lowest levels of the factors the enzyme did not formed $\gamma$-CD, but the concentration of the main product was only $2.20 \mathrm{mg} / \mathrm{ml}$ (Table IV). This was probably due to the characteristic feature of CGTase from B. megaterium to form $\beta$ - and $\gamma$-CD in a certain ratio independently of the reaction conditions.

The established considerations are presented graphically in Fig. 1. It can be seen that formation of $\beta-C D$ does not depend on $\mathrm{pH}$ in the interval from 5.0 to 9.0. The ratio of the other two types of CD was significantly influenced by this factor. At low values of $\mathrm{pH}$ CGTase formed predominantly a-CD, and at high values of $\mathrm{pH}$ it produced $\gamma$-CD. A change in the ratio of $\mathrm{CD}$ depending on $\mathrm{pH}$ of the reaction mixture was reported for other CGTases as well (Atanasova et al., 2009; Martins and Hatti-Kaul, 2003).

The mathematical models developed can be used also for determination of the conditions in which CGTase formed maximal amount of $\alpha$ - and $\gamma$-CD, which are not the predominent product of the reaction. This application of the models is not only important in the theoretical aspect. It has a practical impact if the process for $\mathrm{CD}$ production is performed with the aim of maximal conversion of the substrate in $\mathrm{CD}$, independently of the ratio of the products.

The effect of starch and CGTase concentrations on $\alpha$ - and $\gamma$-CD production at optimal $\mathrm{pH}$ is presented in Fig. 2. Data about $\beta$-CD was not included, since their production was investigated in a previous research (Zhekova et al., 2008). 

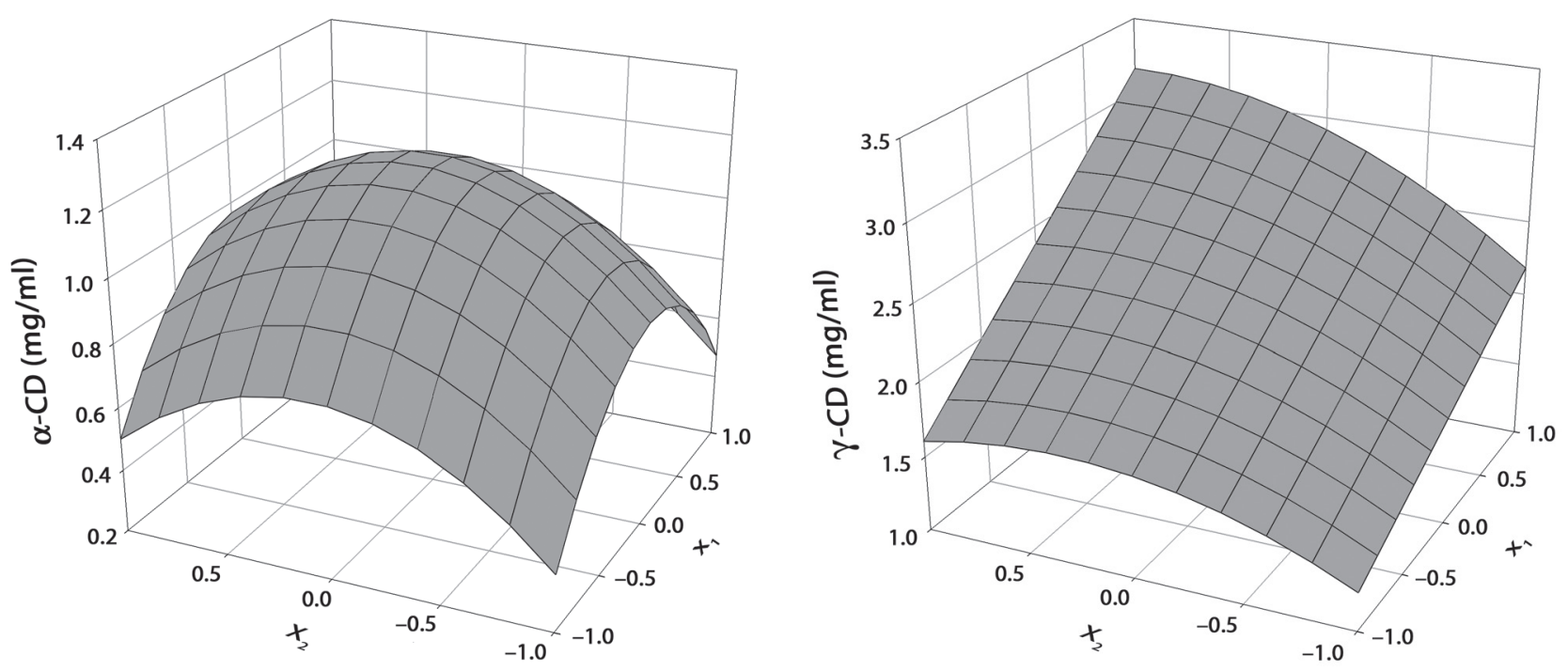

Fig. 2. Effect of starch $\left(x_{1}\right)$ and CGTase $\left(x_{2}\right)$ concentration on production of (a) $\alpha$-CD and (b) $\gamma$-CD at optimal pH values ( $\mathrm{pH} 5.0$ and $\mathrm{pH} 9.0$ respectively).

The increase in starch concentration led to an enhancement of the two types of $\mathrm{CD}$. With regard to $a-C D$ (Fig. 2a) a presence of a saturation substrate concentration $(3.44 \%)$ was observed. This may be due to substrate or product inhibition of a-CD forming activity of the enzyme. In the case of $\gamma$-CD production no saturation of the substrate was reached in the interval of the experiment.

CGTase concentration had an effect on $\alpha$-CD formation up to $2.8 \mathrm{U} / \mathrm{g}$, and it influenced $\gamma$-CD yield up to $3.47 \mathrm{U} / g$. In a previous research a similar dependence was established for $\beta$-CD. The reason for this fact was found to be product inhibition of CGTase by $\beta-C D$ (Zhekova et al., 2008). Probably $\alpha$ - and $\gamma$-CD forming activities of the enzyme were also inhibited by the corresponding type of product. Similar results were established for other CGTases (Gawande and Patkar, 2001; Tomita et al., 1990).

Maximal sum of the concentrations of the three types of CD $22.94 \mathrm{mg} / \mathrm{ml}\left(\hat{Y}_{1}=1.24 \mathrm{mg} / \mathrm{ml}, \hat{Y}_{2}=18.95 \mathrm{mg} / \mathrm{ml}\right.$ и $\left.\hat{Y}_{3}=2.75 \mathrm{mg} / \mathrm{ml}\right)$ was achieved under the following conditions $x_{1}=1, x_{2}=1$ and $x_{3}=0.202$. This concentration corresponded to $45.88 \%$ conversion degree of starch into $\mathrm{CD}$, which was a good yield taking into account that it was obtained without the use of organic solvents.

The mathematical models developed were used for working out a regression equation for the effect of the factors on the conversion degree of substrate in CD (5):

$$
\begin{aligned}
\%_{\text {conversion }}= & 56.43-10.97 \cdot x_{1}+14.163 \cdot x_{2}+2.06 \cdot x_{3}- \\
& -3.68 \cdot x_{1} \cdot x_{2}+2.99 \cdot x_{1}^{2}-11.8 \cdot x_{2}^{2}-4.66 \cdot x_{3}^{2},
\end{aligned}
$$

Maximal conversion of starch $77.19 \%$ was achieved at $x_{1}=-1, x_{2}=0.753$ и $x_{3}=0.221$. However, under these conditions the sum of the concentrations of the three types of CD was only $8.03 \mathrm{mg} / \mathrm{ml}$. This was probably due to the low level of substrate concentration. In a previous work it was established that increase in starch concentration led to enhancement of concentration of $\mathrm{CD}$, but decreased the conversion degree. The reason for this was the product inhibition of CGTase by $\beta-C D$ (Zhekova et al., 2008).

\section{Conclusions}

Adequate mathematical models for the effect of starch concentration, CGTase dosage and $\mathrm{pH}$ on $\alpha-, \beta$-, and $\gamma$-CD production were developed. They were successfully used for determination of the conditions, in which CGTase formed maximal amount of $\beta-C D$, at possibly minimal concentration of $\alpha$ - and $\gamma$-CD. The ratio of the product can be controlled by change in the $\mathrm{pH}$ of the reaction mixture. Another application of the models was determination of the conditions for maximal conversion of starch into CD. This approach led to $45.88 \%$ degree of substrate conversion, which was a good yield for a process without organic solvents.

\section{Literature}

Alves-Prado H.F., A.A.J. Carneiro, F.C. Pavezzi, E. Gomes, M. Boscolo, C.M.L. Franco and R. da Silva. 2008. Production of cyclodextrins by CGTase from Bacillus clausii using different starches as substrates. Appl. Biochem. Biotechnol. 146: 3-13.

Atanasova N. , T. Kitayska, D. Yankov, M. Safarikova and A. Tonkova. 2009. Cyclodextrin glucanotransferase production by cell biocatalysts of alkaliphilic bacilli. Biochem. Eng. J. 46: 278-285. Charoenlap N., S. Dharmsthiti, S. Sirisansaneeyakul and S. Lertsiri. 2004. Optimization of cyclodextrin production from sago starch. Bioresource Technol. 92: 49-54.

Del Valle E. 2004. Cyclodextrins and their uses: a review. Process Biochem. 39:1033-1046. 
Gawande B. and A. Patkar. 2001. a-Cyclodextrin production using cyclodextrin glycosyltransferase from Klebsiella pneumoniae AS-22. Starch/Stärke 53: 75-83.

Goh K.M, N.M. Mahadi, O. Hassan, R.N.Z.R.A. Rahman and R. Md. Illias. 2007. The effects of reaction conditions on the production of $\gamma$-cyclodextrin from tapioca starch by using a novel recombinant engineered CGTase. J. Mollecul. Catal. B: Enzymatic 49: 118-126.

Kato T. and K. Horikoshi. 1984. Colorimetric determination of $\gamma$-cyclodextrin. Analyt. Chem. 54: 1738-1740.

Kestner A., R. Vokk, E. Papel and A. Papeman. 1989. Determination of cyclodextrin glucanotransferase activity. Prikladnaja Biochimia i Microbiologia, 25: 425-430 (in Russian).

Leemhuis H., R.M. Kelly and L. Dijkhuizen. 2010. Engineering of cyclodextrin glucanotransferases and the impact for biotechnological applications. Appl. Microbiol. Biotechnol. 85:823-835.

Lejeune A., K. Sakaguchi and T. Imanaka. 1989. A spectrophotometric assay for the cyclization activity of cyclomaltohexaose (a-cyclodextrin) glucanotransferase. Analyt. Biochem. 181: 6-11.

Martins R. and R. Hatti-Kaul. 2003. Bacillus agaradhaerens LS-3C cyclodextrin glycosyltransferase: activity and stability features. Enzyme Microbial Technol. 33: 819-827.

Mason R., R. Gunst and J. Hess. 2003. Statistical design and analysis of experiments with applications to engineering and science, John Wiley \& Sons.

Matioli G., G. Zanin and F. De Moraes. 2001. Characterization of cyclodextrin glycosyltransferase from Bacillus firmus strain No 37. Appl. Biochem. Biotechnol. 91-93: 643-654.

Pishtiyski I. and B. Zhekova. 2006. Effect of different substrates and their preliminary treatment on cyclodextrin production. World J. Microbiol. Biotechnol. 22: 109-114.
Pishtiyski I., V. Popova and B. Zhekova. 2008. Characterization of cyclodextrin glucanotransferase produced by Bacillus megaterium. Appl. Biochem. Biotechnol. 144 (3): 263-272.

Qi Q. and W. Zimmermann. 2005. Cyclodextrin glucanotransferase: from gene to applications. Appl. Microbiol. Biotechnol. 66: 475-485.

Rauf Z.A., R.Md. Illias, N.M. Mahadi and O. Hassan. 2008. Experimental design to optimization of beta cyclodextrin production from ungelatinized sago starch. Eur. Food Res. Technol. 226: 1421-1427.

Sakinah A.M.M., A.F. Ismail, O. Hassan, A.W. Zularisam and R.Md. Illias. 2009. Influence of starch pretreatment on yield of cyclodextrins and performance of ultrafiltration membranes. Desalination 239: 317-333.=

Szerman N., I. Schroch, A.L. Rossi, A.M. Rosso, N. Krymkiewicz and S.A. Ferrarotti. 2007. Cyclodextrin production by cyclodextrin glycosyltransferase from Bacillus circulans DF 9R. Bioresource Technol. 98: 2886-2891.

Tomita K., T. Tanaka, Y. Fujita and K. Nakanishi. 1990. Some factors affecting the formation of $\gamma$-cyclodextrin using cyclodextrin glycosyltransferase from Bacillus sp. AL 6. J. Ferment. Bioeng. 70: 190-192.

Tonkova A. 1998. Bacterial cyclodextrin glucanotransferase. Enzyme Microbial Technol. 22: 678-686.

Zhekova B., I. Pishtiyski and V. Stanchev. 2008. Investigation on cyclodextrin production with cyclodextrin glucanotransferase from Bacillus megaterium. Food Technol. Biotechnol. 46: 328-334.

Zhekova B., G. Dobrev, V. Stanchev and I. Pishtiyski. 2009. Approaches for yield increase of $\beta$-cyclodextrin formed by cyclodextrin glucanotransferase from Bacillus megaterium. World J. Microbiol. Biotechnol. 25: 1043-1049. 